bedienen. Natürlich werden dann hier nur in Wasser lösliche schwefelsaure Salze zur Zerlegung in Anwendung zu bringen sein.

Zerlegt man z. B. eine Auflösung von übermangansaurem Baryt durch die entsprechende Menge schwefelsauren Ammoniaks, so erbält man mit Leichtigkeit beim Abdampfen der durch Filtration mittelst Schiesswolle von dem gebildeten schwefelsauren Baryt getrennten Flüssigkeit wohlausgebildete Krystalle von übermangansaurem Ammoniak. Dasselbe lässt sich auch noch durch Zerlegung von übermangansaurem Kali und Chlorammonium darstellen. Versetzt man nämlich eine Auflösung des übermangansauren Kalis mit einem Ueberschuss von Salmiak, dampft das Ganze bis zur Krystallisation ab, so erhält man das übermangansaure Ammoniak in schön ausgebildeten Krystallen, das Chlorkalium bleibt in der Mutterlauge zurück. Um das Salz chemisch rein zu haben, braucht man es nur ein Mal umzukrystallisiren. (l'olyt. Notizbl. 1863.21.)

$B$.

\title{
Ueber das Verhalten der Schwefelsäure zu überman- gansaurem Kali und das Verhalten dieser beiden gemeinsam zu verschiedenen andern Stoffen;
}

\author{
nach R. Böttger.
}

Mengt man in einem Porcellanschälchen, etwa mittelst eines Glasstabes, 2 Gewth. vollkommen staubtrockenes gepulvertes übermangansaures $\mathrm{Kali}$ mit 3 Gewth. Schwefelsäurehydrat bei mittlerer Temperatur, so erhält man ein Gemisch, welches in einer mit einem Glasstopfen versehenen weiten Glasflasche aufbewahrt, in steter. Zersetzung begriffen, wochenlang in Folge der Zerlegung entstandener Uebermangansäure, Sauerstoffgas, und zwar in der bekannten Modification von Ozon aushaucht. Böttger nannte deshalb ein solches Gemisch: „ eine neue, perpetuirliche Ozonquelle, " wies, und zwar 2 Jahre früer schon als Schönbein, nach, wie dieses Gemisch in einem hohen, und zwar weit höherem Grade, als ein Gemisch von doppelt-chromsauren Kali und Schwefelsiure, geeignet sei, die allerauffallendsten Oxydations-Erscheinungen mit anderen Stoffen zu Wege zu bringen.

Das Gemisch von Schwefelsïurehydrat und übermangansaurem Kali besitzt in einem so hohen Grade oxydirende Eigenschaften, dass schon beim blossen Contact desselben 
mit einer grossen Anzahl von Stoffen, insbesondere mit ätherischen Oelen, bei gewöhnlicher mittlerer Temperatur die heftigsten Explosionen, meist unter Entflammung jener Stoffe eintreten, und zwar sehr leicht, wenn man etwa 10 bis 12 Tropfen solcher Oele in ein Porcellanschälchen bringt und sie dann mit so viel von obigem Gemisch beriihrt, als an dem Ende eines in dasselbe cingetauchten Platinstäbchens hängen bleibt:

Folgende Oele verursachen bei der Berührung mit genanntem Gemenge Explosionen: Thymianöl, Muskatblüthöl, rectificirtes Terpentinöl, Spiköl, Dostenöl, Zimmtöl, Rautenöl, Citronenöl.

Mit folgenden Oelen erfolgt meist nur, besonders wenn ein wenig davon auf Fliesspapier getröpfelt und dann mit dem Gemisch berührt wird, eine Entzündung ohne Explosion: Rosmarinöl, Lavendelöl, Nelkenöl, Rosenöl, Geraniumöl, Kümmelöl, Cajeputöl, rectificirtes Steinöl, u. a. m.

Alkohol, Aether, Holzgeist, Benzol, Schwefelkohlenstoff entzïnden sich blitzschnell ohno Explosion.

Trocknes Fliesspapier fängt an zu glimmen; Baumwolle entzündet sich, Schiesswolle und Sichiesspulver dagegen entzünden sich nicht.

Staubtrocknes übernangansaures Kali mit trockner Gallussäure zusammengerieben, entzündet sich unter Funkensprühen, mit Tannin gerieben, erfolgt eine Entzündung meist mit Flamme.

Bringt man das genannte Gemisch in ein auf einem Teller stehendes Porcellanschïlchen, fügt dann mittelst einer Pipette 2 bis 3 Tropfen Wasser dazu und überstiilpt dann schnell das Schälchen mit einer hohen Glasglocke, so sieht man prächtig rothgefärbte Dämpfe emporsteigen und theilweise an den Innenwänden der Glasglocke sich zu rothen Tröpfchen verdichten. (Polyt. Centrbl. 1863. 21.)

B.

\section{Ueber die Imwandlang des weichen Eisens in krystal- linisches Risen; von Lewis Thompson.}

Bekanntlich wirken anhaltende Erschütterungen, wie Stoss, Schlag u.s.w., auf weiches geschmeidiges Eisen in der Art, dass dasselbe krystallinisch und brüchig wird. Diese Veränderung resp. diese Abnahme von Festigkeit schreibt der Verf. der Einwirkung des Erdmagnetismus zu, da ein ähnliches Verhalten bei den bis zum 